\title{
Study protocol of the iMPaCT project: a longitudinal cohort study assessing psychological determinants, sexual behaviour and chlamydia (re)infections in heterosexual STI clinic visitors
}

Daphne A. van Wees ${ }^{1 *}$ (D), Janneke C. M. Heijne', Titia Heijman², Karlijn C. J. G. Kampman³, Karin Westra ${ }^{4}$, Anne de Vries ${ }^{5}$, Mirjam E. E. Kretzschmar ${ }^{1,6}$ and Chantal den Daas ${ }^{1,7}$

\begin{abstract}
Background: Chlamydia trachomatis (chlamydia), the most commonly reported sexually transmitted infection (STI) in the Netherlands, can lead to severe reproductive complications. Reasons for the sustained chlamydia prevalence in young individuals, even in countries with chlamydia screening programs, might be the asymptomatic nature of chlamydia infections, and high reinfection rates after treatment. When individuals are unaware of their infection, preventive behaviour or health-care seeking behaviour mostly depends on psychological determinants, such as risk perception. Furthermore, behaviour change after a diagnosis might be vital to reduce reinfection rates. This makes the incorporation of psychological determinants and behaviour change in mathematical models estimating the impact of interventions on chlamydia transmission especially important. Therefore, quantitative real-life data to inform these models is needed.
\end{abstract}

Methods: A longitudinal cohort study will be conducted to explore the link between psychological and behavioural determinants and chlamydia (re)infection among heterosexual STI clinic visitors aged 18-24 years. Participants will be recruited at the STI clinics of the public health services of Amsterdam, Hollands Noorden, Kennemerland, and Twente. Participants are enrolled for a year, and questionnaires are administrated at four time points: baseline (before an STI consultation), three-week, six-month and at one-year follow-up. To be able to link psychological and behavioural determinants to (re)infections, participants will be tested for chlamydia at enrolment and at six-month follow-up. Data from the longitudinal cohort study will be used to develop mathematical models for curable STI incorporating these determinants to be able to better estimate the impact of interventions.

Discussion: This study will provide insights into the link between psychological and behavioural determinants, including short-term and long-term changes after diagnosis, and chlamydia (re)infections. Our mathematical model, informed by data from the longitudinal cohort study, will be able to estimate the impact of interventions on chlamydia prevalence, and identify and prioritise successful interventions for the future. These interventions could be implemented at STI clinics tailored to psychological and behavioural characteristics of individuals.

Trial registration: Dutch Trial Register NTR-6307. Retrospectively registered 11-nov-2016.

Keywords: Chlamydia trachomatis, Sexually transmitted diseases, Reinfection, Psychological determinants, Sexual behaviour, Behaviour change, STI clinic, Mathematical model

\footnotetext{
* Correspondence: daphne.van.wees@rivm.nl

${ }^{1}$ Centre for Infectious Disease Control, National Institute for Public Health

and the Environment, Bilthoven, The Netherlands

Full list of author information is available at the end of the article
}

(c) The Author(s). 2018 Open Access This article is distributed under the terms of the Creative Commons Attribution 4.0 International License (http://creativecommons.org/licenses/by/4.0/), which permits unrestricted use, distribution, and reproduction in any medium, provided you give appropriate credit to the original author(s) and the source, provide a link to the Creative Commons license, and indicate if changes were made. The Creative Commons Public Domain Dedication waiver (http://creativecommons.org/publicdomain/zero/1.0/) applies to the data made available in this article, unless otherwise stated. 


\section{Background}

Chlamydia trachomatis (chlamydia) is the most commonly diagnosed bacterial STI among young heterosexual men and women in many western countries, including the Netherlands with up to 55,000 diagnosed infections in STI clinics nationally each year [1]. Control of this infection is of public health importance, because it can cause severe reproductive complications, including pelvic inflammatory disease (PID), ectopic pregnancy and tubal subfertility [2-5]. However, it is unclear why the prevalence of chlamydia remains unchanged even in countries with chlamydia screening programs, such as England, Australia, Canada, and the United States [6].

A difficulty in controlling chlamydia transmission is that most infections are asymptomatic [7]. Since people are unaware of their infection, initiation of preventive behaviours (i.e., condom use), or health-care seeking behaviour (i.e., chlamydia testing), mostly depends on psychological determinants, such as risk perception, self-efficacy or attitudes regarding condom use [8-11]. Previous studies have mainly focussed on identifying behavioural risk factors for chlamydia infection [12-15], while understanding how psychological determinants influences such behaviour might be more informative for the development of effective interventions [10]. For example, an increased number of sexual partners has previously been identified as a risk factor for chlamydia infection [12, 14], but having many sexual partners might not necessarily be risky if people would realistically perceive their risk for acquiring a STI and take the necessary steps to protect themselves. Therefore, studying the link between psychological determinants and behaviour and relating these to chlamydia infections might increase our understanding of chlamydia transmission. For instance, many young people tend to underestimate their personal risk of acquiring chlamydia $[8,16]$, which could have a negative effect on their condom use and testing uptake $[8,10,17]$.

Another reason for the sustained chlamydia prevalence might be high reinfection rates after treatment or natural clearance $[15,18-20]$.To reduce the risk of reinfections, behaviour change (i.e., more consistent condom use) might be essential [21, 22]. Several studies have shown that individuals who were diagnosed with an STI were more likely to change into less risky sexual behaviour after they received the test results than individuals who tested negative [21, 23-27], but the influence of STI test results on underlying psychological determinants are not known. Behaviour change might be dependent on a number of psychological determinants, such as risk perception, perceived norms, perceived susceptibility, self-efficacy, knowledge, intentions, and attitudes regarding condom use $[8-11,17]$. For example, while increased perceived risk of STI as a result of a positive diagnosis might induce behaviour change, receiving negative test results could lead to a false sense of security in high-risk individuals, and changing their risky sexual behaviour after the STI test may be deemed unnecessary [24]. However, regardless of the diagnosis, fear experienced before receiving the STI test results [17], might provide enough motivation to increase condom use. Quantitative longitudinal data is needed to explore the interplay between psychological and behavioural determinants after diagnosis and over time.

Longitudinal data on psychological and behavioural determinants could be used to investigate the impact of interventions aimed at reducing chlamydia (re)infections in mathematical models. Mathematical models are a tool for understanding the transmission of infectious diseases and establish a scientific basis for decision-making [28]. Predictions of the impact of interventions on prevalence arising from these models can be used to inform national health policies $[29,30]$. However, psychological determinants are hardly ever incorporated in mathematical models describing STI transmission, and many models do not take into account that behaviour can change over time. Incorporating psychological determinants and behavioural change might improve the estimation of the impact of interventions on chlamydia prevalence in mathematical models. It may also increase our understanding on how to control chlamydia transmission more effectively, for example by identifying core risk groups that contribute most to transmission.

To explore the link between (changes in) psychological and behavioural determinants, and chlamydia (re)infection, a study called 'Mathematical models incorporating Psychological determinants: control of Chlamydia Transmission' (iMPaCT) was initiated. A longitudinal cohort study will be conducted among individuals testing for chlamydia at the STI clinic. Individual data on (re)infection rates, psychological determinants, and behaviour will be collected at different points in time to link these to chlamydia (re)infections and to study changes over time. These changes include short-term changes after a diagnosis, and long-term changes (1 year after a diagnosis at baseline). Mathematical models will be developed incorporating psychological and behavioural determinants using data from the longitudinal study. We will explore how incorporating these variables, including short- and long-term changes, influence chlamydia prevalence estimations from models.

\section{Methods}

\section{Study aim}

The aim of the iMPaCT study is to explore the link between psychological and behavioural determinants, and chlamydia (re)infection among heterosexuals aged 
18-24 years visiting STI clinics. The following aims will be addressed:

1. To identify predictors of chlamydia infection;

- What demographic, psychological, and behavioural determinants are associated with chlamydia infection?

2. To investigate short-term and long-term changes (or stability) in psychological determinants and sexual behaviour over time;

- What is the influence of a chlamydia test result (positive or negative) on psychological determinants and subsequent sexual behaviour?

- Regarding these determinants, does change (or stability) in psychological and/or behavioural determinants affect the probability of reinfection?

- How do psychological and behavioural determinants change over time during 1 year of follow-up?

3. To explore the influence of psychological determinants on the predicted impact of intervention measures to reduce chlamydia transmission by mathematical models;

4. To explore the influence of changes in psychological determinants and sexual behaviour on the predicted impact of intervention measures to reduce chlamydia transmission by mathematical models.

\section{Design}

A longitudinal cohort study will be conducted among young heterosexual STI clinic visitors in the Netherlands.

\section{Setting}

Participants will be recruited from STI clinics of the Public Health Services (GGD) of Amsterdam, Kennemerland, Hollands Noorden, and Twente. In 2015, these STI clinics tested around 20,000 heterosexual men and women under the age of 25 for chlamydia according to the national registry. The majority of this group was female, $\geq 20$ years old, and Dutch, and approximately $15 \%$ tested positive for chlamydia [31].

\section{Study population}

Heterosexual men and women aged 18 to 24 years visiting the STI clinic of the GGD Amsterdam, Kennemerland, Hollands Noorden, or Twente are eligible to participate. All enrolled individuals will be invited for follow-up data collection moments, irrespective of their test result at baseline. Individuals, who are not living in the Netherlands, are not able to read or speak Dutch, commercial sex workers, men who have sex with men (including men who have sex with both men and women), and women who have sex with women, will be excluded from participation in this study. Women who have sex with both men and women will only be excluded if their last three partners were women.

\section{Recruitment}

Participants will be recruited during the process of making an appointment at the STI clinic. To fit the study into the daily flow of the STI clinics, two different procedures will be applied. At the GGD Amsterdam, Kennemerland, and Hollands Noorden, individuals who are eligible to participate will be invited during the process of making an appointment online. Individuals will receive information about $\mathrm{iMPaCT}$ when they confirm their appointment. At the GGD Twente, the receptionist will invite individuals who are eligible to participate when they are making an appointment by telephone, and send them an email with information about iMPaCT. Recruitment is expected to take approximately 6 to 8 months.

\section{Inclusion and follow-up}

Participants will be enrolled for 1 year, and data on (re)infection rates, psychological determinants, and behaviour will be collected at four different points in time to link these to chlamydia (re)infections and study changes (or stability) in psychological determinants and sexual behaviour over time. Data collection will occur at the following time points: at baseline, three-week follow-up, six-month follow-up and at one-year follow-up (Fig. 1).

At baseline, individuals eligible to participate will be invited during the process of making an appointment at the STI clinic. If an individual agrees to participate, an online questionnaire (the questionnaire is described in more detail below) will be administered, which starts after participants gave informed consent. Subsequently, participants are tested for chlamydia at the STI clinic. During the consultation at the STI clinic, the participants will receive information on prevention of STI and motivational-interviewing based counselling from the nurses. Since this might have an effect on psychological and behavioural determinants [32] and possibly lead to biased answers, participants will complete the baseline questionnaire before the consultation. Therefore, participants have approximately 1 to 2 weeks to fill out the questionnaire, between making their appointment and their STI clinic visit. Individuals who agree to participate will receive an email, as a reminder, with information about $\mathrm{iMPaCT}$ and a web link, which will guide them directly to the online questionnaire. Participants, who completed the questionnaire after their consultation at the STI clinic, will be excluded.

The participants will receive the chlamydia test results within 2 weeks of the STI clinic visit. Approximately 1 


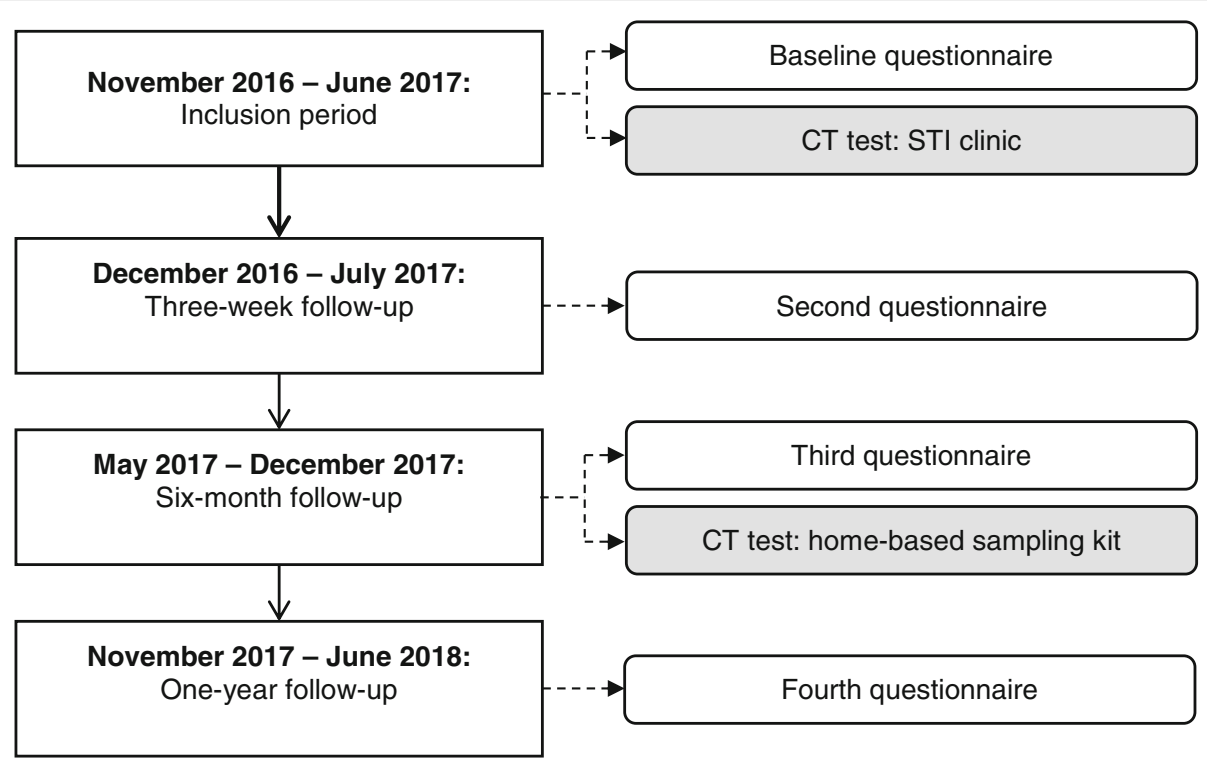

Fig. 1 Flowchart of the longitudinal cohort study. CT= Chlamydia trachomatis

week after the communication of the test results (three to 4 weeks after the STI clinic visit), all participants who completed the baseline questionnaire will be invited via email to fill out the second questionnaire online. Participants, who have not finished the second questionnaire, will receive two reminders by email: 1 week and 2 weeks after the invitation for the second questionnaire.

The third data collection moment will take place 6 months after baseline, because reinfections usually occur within 6 months after the initial infection $[15,18,33$, 34]. Firstly, all participants who completed the baseline questionnaire will be invited via email to fill out an online questionnaire. Additionally, all participants will be invited for a retest, irrespective of the test result at baseline. They will receive a self-swab test-kit at their home address or another preferred address, as specified in the third questionnaire, in a plain package fitting letterboxes. In this package, the participants will find simple instructions about the type of sample that they need to provide (urogenital test only, urine sample for men and vaginal swab for women) and how to collect these samples. Subsequently, the participants mail the testing-kits directly to the laboratory for chlamydia and gonorrhoea testing. The results will be communicated within three working days after the arrival of their material in the laboratory, via email with a link to a secured webpage, where the participants can download the results of their test with the login data attached in the email. Participants, who have not finished the online questionnaire, will receive two reminders by email: 1 week and 2 weeks after the invitation for the third questionnaire. Participants, who have completed the online questionnaire, but who have not mailed the test-kit to the laboratory, will receive two reminders by email: 2 weeks and 4 weeks after the test-kits are sent. The number of reminders for the retest will be the same as the number of reminders for the questionnaires, but the reminders will be spread further apart due to the possibility of delays in the logistics of the retest. Participants, who test positive, will be advised to make an appointment with their GP or at the STI clinic for appropriate treatment. A letter for the GP or STI clinic with information about the iMPaCT study, and a copy of the laboratory results will be provided.

Finally, 1 year after baseline, all participants who completed the baseline questionnaire will be invited via email to fill out the fourth online questionnaire. Participants, who have not finished the online questionnaire, will receive two reminders by email: 1 week and 2 weeks after the invitation for the fourth questionnaire. After completing the last questionnaire, irrespective of completing the three-week and six-month follow-up questionnaires, participants will receive a gift voucher with a value of $€ 5$ within a week (by mail).

\section{Demographic and consultation information}

National STI surveillance data will be used to complement the information gathered in the questionnaires. This surveillance data includes routinely registered data of all consultations from all STI clinics in the Netherlands, such as demographic information (i.e. age, sex, ethnicity and level of education), previous testing behaviour, previous STI diagnosis, reason for testing (i.e., notified by chlamydia-positive partner, symptoms), several behavioural determinants and STI test results. In the surveillance data, each STI clinic visitor has an anonymous identification (ID) number. This ID number 
will automatically be incorporated in the web link to the questionnaire, which enables linkage of the surveillance data to the questionnaire. To identify chlamydia reinfections before the retest at six-month follow-up, information on STI clinic visits between baseline and six-month follow-up of the participants will also be extracted from the national STI surveillance data using this ID number, including the reason for their visit and the test result.

\section{Laboratory testing}

The chlamydia-test performed at baseline is routine practice of the consultation at the STI clinic, using nucleic acid amplification tests (NAAT) to detect chlamydia, such as Transcription-mediated amplification (TMA) or polymerase chain reaction (PCR). Six months after baseline, all participants will be invited for a retest, irrespective of the test result at baseline. Home-based sampling and returning test kits to a laboratory by mail can be used to test for STI, such as chlamydia and gonorrhoea [18, 35-39]. The testing-kits can be mailed directly to the laboratory using the pre-paid return envelope provided. All samples will be tested for chlamydia and gonorrhoea using NAAT/PCR, with respectively a sensitivity of 97.0 and $99.3 \%$ and specificity of 98.9 and $99.3 \%$ [38].

\section{Defining chlamydia (re)infection}

Chlamydia infection at baseline will be defined as confirmed positive NAAT-results for Chlamydia trachomatis at any anatomic location (urogenital, anorectal, pharyngeal) at the STI clinic. Chlamydia reinfection will be defined as confirmed positive NAAT-result for Chlamydia trachomatis based on either the samples provided by the participants at six-month follow-up through the self-swab testing kit (urogenital only) and/or a test at the STI clinic between baseline and six-month follow-up at any anatomic location (urogenital, anorectal, pharyngeal).

\section{Questionnaires}

We have conducted a pilot survey in May 2016 among 296 heterosexuals aged 16-34 to evaluate the conciseness and the comprehensibility of the online questionnaire using factor and reliability analysis and comments from the respondents. People were recruited via social media and at a vocational school in Amersfoort, the Netherlands. The duration of the questionnaires in the $\mathrm{iMPaCT}$ study was estimated based on the results from this pilot survey; the questionnaire at baseline will take about 10-15 min and the other questionnaires will take less than $10 \mathrm{~min}$. All questionnaires will be sent via Formdesk [40], a tool to create and manage online forms. Each participant has an anonymous study ID number, which will be used to link the questionnaire data from Formdesk to the information in the national STI surveillance data.
The baseline questionnaire has two parts: one part on psychological determinants, and one part on sexual behaviour. Psychological determinants included in the questionnaires that might play a role in acquiring STI are; risk perception [41-45], impulsiveness [46-50], intentions regarding condom use $[11,51]$, attitudes regarding prevention of chlamydia $[52,53]$, health goals $[9,51]$, knowledge [11], stigma [54-56], shame [54-56], anxiety [54-56], self-efficacy [43, 57], social support [11], peer norms [11] and self-esteem [58]. These determinants were included in the questionnaire based on associations in the literature with sexual risk behaviour, testing-behaviour, and behavioural change. Answers to these questions are measured on a 5-point Likert scale.

The questions about sexual behaviour are based on several validated questionnaires, including questionnaires from previous STI studies [11, 59-61], and the UK NATSAL [13]. Participants will be asked about the number of sex partners, age at sexual debut, condom use, and we will pose detailed questions on the last three partners, including begin and end of the partnership, condom use, sex frequency, type of sex, and partner characteristics.

The follow-up questionnaires will be the same as the baseline questionnaire, with a few additional questions. To explore short-term effects of diagnoses (and if applicable treatment) on possible changes in psychological and sexual behaviour determinants, the questionnaire at three-week follow-up will include the same questions on psychological determinants and sexual behaviour as the baseline questionnaire. For participants who test positive at baseline, questions are added about partner notification in the week following treatment. In the questionnaire at six-month and one-year follow-up, questions will be added about visits to the STI clinic between baseline and six-month follow-up and between six-month follow-up and one-year follow-up, including test results, treatment, and reasons for the visit(s).

\section{Expected response}

Based on the number of consultations at the STI clinics of the public health services in Twente, Hollands Noorden, Kennemerland and Amsterdam in the last 6 months of 2015 in the national registry, around 10,000 heterosexual STI clinic visitors will meet the inclusion criteria during 6 months of recruitment (40\% men and 60\% women). Table 1 shows the expected response for each data collection moment by STI clinic. The response rate at baseline is expected to be low, because recruitment at baseline is internet-mediated (passive recruitment) and there will be no face-to-face interaction with potential participants $[62,63]$. We aim to include 2000 people at baseline (20\% response rate), of which 800 are men and 1200 are women, based on the distribution of heterosexual male and female visitors at the STI clinics [31]. We 
Table 1 Expected number of participants per STI clinic at each follow-up moment

\begin{tabular}{|c|c|c|c|c|c|c|}
\hline \multirow[t]{2}{*}{ STI clinic } & \multicolumn{6}{|c|}{ Expected number of participants } \\
\hline & Baseline (men/women) & Baseline $\mathrm{Ct}+$ & Three-week & Six-month & Six-month $\mathrm{Ct}+$ & One-year \\
\hline Twente & $400(160 / 240)$ & 60 & 320 & 193 & 31 & 120 \\
\hline Hollands Noorden & $400(160 / 240)$ & 60 & 320 & 193 & 31 & 120 \\
\hline Kennemerland & $400(160 / 240)$ & 60 & 320 & 193 & 31 & 120 \\
\hline Amsterdam & $800(320 / 480)$ & 120 & 640 & 385 & 62 & 240 \\
\hline Total & $2000(800 / 1200)$ & 300 & 1600 & 964 & 155 & 600 \\
\hline
\end{tabular}

Abbreviations: $\mathrm{Ct}+$ chlamydia positive

expect $15 \%$ of the participants at baseline to test positive $(N=300)$ [31].

The response rates at the follow-up moments are expected to be higher than at baseline, because the participants will receive personal invitations by email instead of the impersonal baseline invitation addressed to all the STI clinic visitors who were eligible to participate. However, the response rates might decline over time [30]. At three-week follow-up, a response rate of $80 \%(N=1600)$ is expected (this includes sending reminders) [30]. All participants will be contacted by email again at the six-month follow-up, also participants who did not respond to the three-week follow-up. The participation rate at six-month follow-up among people who tested chlamydia positive at baseline is expected to be around $66 \%$ [18], and the participation rate is likely to be lower for individuals who tested chlamydia negative at baseline [24] and is expected to be around 45\%. Therefore, approximately 1000 participants will be tested for chlamydia at six-month follow-up. We expect $15 \%$ of the participants that were chlamydia negative (Ct-) at baseline and $20 \%$ of the participants that were chlamydia positive $(\mathrm{Ct}+)$ at baseline to test positive at six-month follow-up $(N=155)[31,33,34]$. All participants who completed the baseline questionnaire will be contacted again at the one-year follow-up, also participants who did not respond to the three-week follow-up and/or the six-month follow-up, and we expect a response rate of $30 \%(N=600)$. Participants can choose to leave the study at any time for any reason. If participants formally withdraw from the study by email, they will not be invited for follow-up data collection.

\section{Sample size and power calculations}

To explore if the study population will be large enough to detect differences in psychological and behavioural determinants between baseline and six-month follow-up with adequate statistical power, sample size and statistical power calculations were performed in Stata version 13.0 [64]. Firstly, sample size calculations for at least $80 \%$ power were performed for the participants who tested positive $(\mathrm{Ct}+)$ and participants who tested negative for chlamydia at baseline (Ct-), assuming a type I error $(\alpha)$ of
0.05, 34\% loss to follow-up after 6 months in the $\mathrm{Ct}+$ group, and 55\% loss to follow-up after 6 months in the Ct- group (based on the expected response rates described above). Secondly, power calculations were performed with the expected sample size of 2000 participants at baseline, assuming $15 \%$ chlamydia positivity $(n=300)$ [31].

The sample size and power calculations for sexual behaviour were calculated with condom use as an example. Soetens et al., (2015) [26] found that condom use 1 year after the chlamydia test at baseline increased in the $\mathrm{Ct}+$ group and decreased in the Ct- group. Based on these results, the percentage of participants in our study using a condom with the last sexual contact was assumed to increase in individuals after a $\mathrm{Ct}+$ baseline test and decrease in individuals after a Ct- baseline test. The sample size and power for sexual behaviour were calculated for three different scenarios: 10 (scenario 1), 15 (scenario 2), or 20 (scenario 3) percent change at six-months follow-up (Table 2).

This is, to our knowledge, the first study assessing changes in psychological determinants after diagnosis of chlamydia or over a longer period of time. Therefore, no literature is available to inform possible changes in psychological determinants in our sample size calculations. The sample size and power calculations for the psychological determinants were calculated with risk perception as an example, but this can also be generalised to other psychological determinants. Research has shown that people chronically underestimate their personal risk of acquiring chlamydia [8]. Tailored risk information (i.e. after a consultation at the STI clinic) might increase an individual's perceived risk for STI [65]. Furthermore, individuals with previous STI diagnoses are more likely to report higher perceived risk for STI than those with no previous STI diagnoses [66, 67]. Therefore, we hypothesized that risk perception, which will be assessed in the questionnaire as the estimated personal risk of chlamydia on a scale from 0 to 100 , might increase in individuals after a $\mathrm{Ct}+$ baseline test and decrease in individuals after a Ct-baseline test. The sample size and power for the psychological determinants were calculated with the same hypothesized percent change as for sexual behaviour (Table 2). 
Table 2 Sample size and power calculations for different scenarios

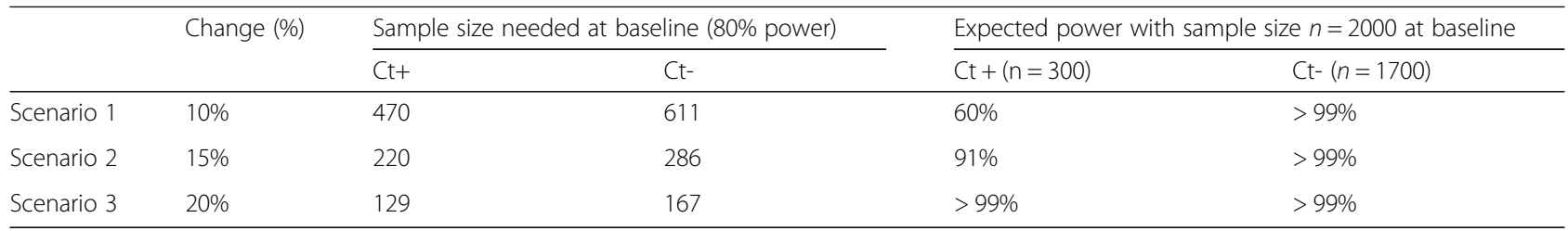

Sample size and power calculations to detect a change in psychological determinants or sexual behaviour at six-month follow-up with at least $80 \%$ power, assuming $34 \%$ loss to follow-up in the chlamydia positives ( $\mathrm{Ct}+$ ) and $55 \%$ loss to follow-up in the chlamydia negatives (Ct-) Abbreviations: Ct+ chlamydia positive, Ct- chlamydia negative

The expected sample size of 2000 participants will be large enough to detect a change of $10-20 \%$ in psychological determinants and behavioural with adequate statistical power (power $>80 \%$ ). The expected sample size of 300 in the $\mathrm{Ct}+$ group is too small for detecting $10 \%$ change (scenario 1) for $\geq 70 \%$ power, but the expected sample size is sufficient for detecting $\geq 15 \%$ change (scenario 2 and 3 ), which might be more likely in this group [26].

\section{Statistical analyses}

The main analysis will include all participants who completed the baseline questionnaire, irrespective of their test result. Possible response bias will be explored in a (non-)response study using anonymised national STI surveillance data of all individuals eligible to participate who visited the STI clinic in the inclusion period. Demographic characteristics, sexual behaviour, and STI consultation information will be compared between participants who completed the baseline questionnaire, and all the STI clinic visitors who were invited to participate, but did not complete or start the baseline questionnaire. The participants who completed the baseline questionnaire will be identified in the surveillance data, using the previously described ID number incorporated in the web link to the questionnaire.

We expect only few missing values in the completed baseline questionnaires, because each question has to be answered before the next question appears. Furthermore, data consistency checks will be incorporated in the online questionnaire. Missing values in variables extracted from the national STI surveillance data or in the second, third and last questionnaire due to loss to follow-up will be included as a separate category if more than $5 \%$ is missing.

Baseline characteristics of the study population will be presented, using summary statistics, including means, standard deviations, medians and ranges for continuous variables and frequency distributions for binary and categorical variables. To identify predictors of participation in the (non-)response study, and to identify predictors of chlamydia (re)infection, univariable and multivariable logistic regression analysis will be performed. In the univariable analysis, variables significantly associated with the outcome (participation or chlamydia (re)infection) will be included in the multivariable models.
Multivariable models will be constructed using a backward elimination procedure. Statistical significance will be defined as a $p$-value $\leq 0.1$, and odds ratios and $95 \%$ confidence intervals of each predictor variable will be reported. Covariates based on a priori hypotheses will be examined as potential confounder or effect modifiers in the models.

To identify distinct risk groups for chlamydia (re)infection, based on the results of the multivariable logistic regression analysis, we will use latent class analysis for multivariable categorical data. In this analysis, underlying dimensions (latent classes) of the dependent variables can be inferred based on patterns in the observed data. The latent classes arising from this analysis could be combinations of several measured psychological, behavioural and demographic variables. Covariates that are independent of the outcome, but might influence the latent classes will be included in the analysis. The number of latent classes will be determined by increasing the number of classes until the best fitting model has been found, using the Bayesian Information Criterion (BIC) to assess the goodness of fit. The latent classes can be used to define distinct sexual risk profiles, which can be implemented in future mathematical models.

To explore changes in psychological determinants and sexual behaviour over time using data from the three-week, six-month, and one-year follow-up moments, and to identify risk profiles for chlamydia reinfection, we will use latent transition analysis, which is an extension of the latent class analysis described above. In this analysis, movement from one latent class to another over time can be determined. Similar to the latent class model, the BIC will be used to assess how well the latent transition model fits the observed data. The estimated transition probabilities can be implemented in future mathematical models of the transmission of chlamydia, which might enable us to better capture the complexity of sexual behaviour.

\section{Mathematical model}

The mathematical model will be a pair compartmental model representing a heterosexual population of men and women aged 18-24 years. Chlamydia will be described with a susceptible-infected-susceptible (SIS) structure. The infection parameters for chlamydia are 
reasonably well established and will be used from the available literature. The transmission rate per sex act will be calibrated to the positivity rate found at baseline. The model population will be subdivided into risk groups according to the risk classes identified in the latent class model (based on psychological and behavioural determinants from the baseline questionnaire).

Behavioural change after a diagnosis and in time will be incorporated by moving people from one risk group to another based on the latent transition model. First, we will explore the influence of a diagnosis on short-term changes of psychological and behavioural determinants in the model. This data will be based on differences between the baseline, three-week, and the six-month follow-up questionnaires. Second, we will theoretically explore the effect of long-term behaviour change on the impact of intervention measures, using the questionnaire data at one-year follow-up.

\section{Discussion}

The iMPaCT study will provide insights into the link between psychological determinants and sexual behaviour, behavioural change, and chlamydia (re)infections. We propose that incorporating these determinants in mathematical models will improve the impact assessment of interventions aimed at reducing chlamydia transmission. Chlamydia interventions that have been applied in practice have mainly focused on increasing testing uptake, and previous mathematical modelling studies have shown that, depending on the coverage of chlamydia testing in the general population, testing and treatment could be an effective strategy to reduce chlamydia prevalence, $[30,68$, 69]. However, empirical studies have established that the coverage of chlamydia testing has not been high enough to observe a significant reduction in the population prevalence of chlamydia [13, 61, 70]. Therefore, a paradigm shift is needed to control chlamydia transmission more effectively. For example, interventions could be focused on increasing testing uptake among core risk groups based on psychological and behavioural characteristics to prevent reinfection after a diagnosis. Our mathematical model informed by the data of the cohort study will be able to estimate the impact of such interventions on chlamydia prevalence, and identify and prioritise successful interventions for specific risk groups, which might lead to more efficient ways to control chlamydia transmission. Subsequently, these interventions could be implemented at STI clinics tailored to psychological and behavioural characteristics of individuals.

\section{Strengths}

This is the first longitudinal cohort study investigating short-term and long-term changes in psychological determinants and sexual behaviour after chlamydia diagnosis.
The prospective study design of this study with repeated measurements, namely the follow-up questionnaires and the retest, and the combination of an extensive selection of psychological determinants will expand our knowledge of risk factors for (re)infection. Another strength of this study is the combination of two data sources: longitudinal questionnaire data on psychological determinants and sexual behaviour, and national STI surveillance data on demographics, previous testing behaviour, and laboratory confirmed STI diagnosis. Therefore, we are able to obtain extensive knowledge with a relatively concise questionnaire, because questions on demographics, previous testing behaviour, STI diagnosis and other variables that are available in the national STI surveillance could be omitted in the online questionnaire.

The pilot survey, which has been conducted a few months before the start of iMPaCT study, enabled us to improve the comprehensibility of the questionnaire. This, in combination with sending reminder emails and offering incentives (gift voucher, free home-based sampling kit), might lead to higher response and completion rates [71]. Furthermore, the psychometric evaluation of the pilot survey and the advantages of using online questionnaires, such as programmed warning alerts to prevent incorrect answers (i.e., number of partners last 6 months can't be higher than the number of partners in the last year), ensured optimal reliability and validity of the longitudinal questionnaire data.

Finally, most mathematical models for infectious disease transmission incorporating behaviour change are entirely theoretical and lack validation with empirical data [72]. Our mathematical model will be informed by real-life data on behaviour change, which might result in more realistic model estimations and the opportunity to validate the model outcomes. The model outcomes could be directly translated into to advice for public health policy makers about effective intervention measures.

\section{Limitations}

First, the questionnaire data is self-reported, which could lead to reporting bias, such as under- or over-reporting of sexual behaviour. Although sexual behaviour in the national STI surveillance data is also self-reported, and thus prone to bias, sexual behaviour in the surveillance data will be matched to sexual behaviour as reported in the questionnaire to check for consistency. Furthermore, being notified for an STI or having STI-related symptoms might affect answers in the questionnaire [54, 67] and this will be taken into account in the statistical analyses. Response bias may also occur, and we will assess this in a (non-)response study by extracting the iMPaCT participants from the national STI surveillance data, and compare demographics, sexual behaviour, and STI consultation information between the participants and all 
eligible STI clinic visitors who were invited to participate, but did not complete or start the baseline questionnaire. We will use this (non-)response study to estimate the generalizability of the iMPaCT study population with reference to all young heterosexual STI clinic visitors and to guide the interpretation of the results. The iMPaCT study population is not likely to be representative of the general population, as STI clinic visitors tend to be more high-risk compared to the general population. However, this group potentially benefits the most from improved interventions. Thus, in this study we will gather detailed information for exactly the group of interest.

Previous longitudinal chlamydia studies have shown that response rates decline over time and our study will most likely not be an exception [18, 30]. To minimize loss to follow-up, free home-based sampling kits and promised monetary incentives will be used to encourage participation rates at six-month and one-year follow-up. The samples size and power calculations, taking loss to follow-up into account, showed that through recruitment at multiple STI clinics in different regions of the Netherlands, a sufficiently large and nationally representative group of STI clinic visitors can be approached for participation in the iMPaCT study.

It is likely that periods of high and low risk behaviour alternate during individual sexual careers [73], such as a period of high risk sexual behaviour after separating from a long standing partnership. Therefore, the timing of the follow-up data collection moments is crucial. For example, it could be argued that the period between the follow-up questionnaire after 3 weeks and baseline is too short to detect changes in sexual behaviour, and the questionnaires 6 months and 1 year after baseline might not be long-term enough to capture changes in people's behaviour that are not necessarily offset by an event such as a diagnosis. However, we speculate that the effect of a positive STI diagnosis on psychological determinants, such as intentions and attitudes regarding condom use, might be strongest in the first few days after receiving the test results. Furthermore, the optimal timing of testing for reinfections is not known, and the recommended timing of retesting across different countries ranges between 3 to 12 months [74, 75]. Therefore, participants will be invited for the retest 6 months after the baseline chlamydia test combined with a questionnaire, and after the same length of time (6 months after the retest), the participants will be invited to fill out the last questionnaire at one-year follow up.

\section{Abbreviations}

BIC: Bayesian information criterion; Ct: Chlamydia trachomatis; GGD: Public health services (in Dutch: Gemeentelijke Gezondheids Dienst);

ID: Identification number; NAAT: Nucleic acid amplification test; NATSAL: The national survey of sexual attitudes and lifestyles; PCR: Polymerase chain reaction; PID: Pelvic inflammatory disease; STI: Sexually transmitted infection; TMA: Transcription-mediated amplification

\section{Acknowledgements}

We are grateful to the staff at the STI clinics of Amsterdam, Kennemerland, Hollands Noorden, Twente, who are involved in the recruitment and data collection of participants, and Marlous Ratten and Klazien Visser from Soapoli-online, who are involved in the coordination of laboratory testing of the home-based sampling kits at six-month follow-up. We also thank the staff at the STI department at the National Institute for Public Health and the Environment, especially Birgit van Benthem.

\section{Funding}

This project is funded by the Strategic Programme (SPR) of the National Institute for Public Health and the Environment (RIVM) (project number S/113004/01/IP). The funders had no role in study design, data collection and analysis, decision to publish, or preparation of the manuscript.

\section{Availability of data and materials}

The dataset (anonymised) generated during this study will be made available for interested parties on request.

\section{Authors' contributions}

$\mathrm{CdD}, J \mathrm{H}$, and DvW coordinate the study and drafted the manuscript. MK has been involved with optimising the study design. TH, KK, KW, and AdV are involved with the coordination of the iMPaCT study recruitment at the STI clinics of Amsterdam, Twente, Hollands Noorden and Kennemerland. All authors reviewed the manuscript and approved the final version for publication.

\section{Authors' information}

Not applicable.

\section{Ethics approval and consent to participate}

This study was approved by the Medical Ethical Committee Noord-Holland, Alkmaar, the Netherlands (NL57481.094.16/M016-026). All participants provide informed consent for participation in $\mathrm{MPaCT}$ online prior to starting the questionnaire (first page of the questionnaire).

\section{Consent for publication \\ Not applicable.}

\section{Competing interests}

The authors declare that they have no competing interests.

\section{Publisher's Note}

Springer Nature remains neutral with regard to jurisdictional claims in published maps and institutional affiliations.

\section{Author details}

${ }^{1}$ Centre for Infectious Disease Control, National Institute for Public Health and the Environment, Bilthoven, The Netherlands. ${ }^{2}$ Public Health Service Amsterdam, Amsterdam, The Netherlands. ${ }^{3}$ Public Health Service Twente, Enschede, The Netherlands. ${ }^{4}$ Public Health Service Hollands Noorden, Alkmaar, The Netherlands. ${ }^{5}$ Public Health Service Kennemerland, Haarlem, The Netherlands. ${ }^{6} J u l i u s$ Centre for Health Sciences and Primary Care, University Medical Centre Utrecht, Utrecht, The Netherlands. ${ }^{7}$ Department of Interdisciplinary Social Science, Faculty of Social and Behavioural Sciences, Utrecht University, Utrecht, The Netherlands.

Received: 22 February 2018 Accepted: 1 November 2018

Published online: 13 November 2018

\section{References}

1. Visser M, Van Aar F, van Oeffelen AAM, Van den Broek IVF, Op de Coul ELM, Hofstraat SHI, et al. Sexually transmitted infections including HIV, in the Netherlands in 2016. Bilthoven: Centre for Infectious Disease Control, National Institute for Public Health and the Environment (RIVM); 2017. Available from: http://www.rivm.nl/Documenten_en_publicaties/ Wetenschappelijk/Rapporten/2017/Juni/Sexually_transmitted_infections_ including_HIV_in_the_Netherlands_in_2016

2. Davies B, Turner KME, Frølund M, Ward H, May MT, Rasmussen S, et al. Risk of reproductive complications following chlamydia testing: a population- 
based retrospective cohort study in Denmark. Lancet Infect Dis. 2016;16(9): 1057-64. https://doi.org/10.1016/S1473-3099(16)30092-5.

3. Haggerty CL, Gottlieb SL, Taylor BD, Low N, Xu F, Ness RB. Risk of sequelae after chlamydia trachomatis genital infection in women. J Infect Dis. 2010; 201(Suppl 2):S134-55. https://doi.org/10.1086/652395.

4. Holmes KK, Sparling PF, Stamm WE, Piot P, Wasserheit JN, Corey L, et al. Sexually transmitted diseases. 4th ed. New York: McGraw-Hill; 2008.

5. Reekie J, Donovan B, Guy R, Hocking JS, Kaldor JM, Mak DB, et al. Risk of pelvic inflammatory disease in relation to chlamydia and gonorrhea testing, repeat testing, and positivity: a population-based cohort study. Clin Infect Dis. 2017. https://doi.org/10.1093/cid/cix769.

6. Unemo M, Bradshaw CS, Hocking JS, de Vries HJC, Francis SC, Mabey D, et al. Sexually transmitted infections: challenges ahead. Lancet Infect Dis. 2017; 17(8):e235-79. https://doi.org/10.1016/S1473-3099(17)30310-9.

7. Gottlieb SL, Martin DH, Xu F, Byrne Gl, Brunham RC. Summary: the natural history and immunobiology of chlamydia trachomatis genital infection and implications for chlamydia control. J Infect Dis. 2010;201(Suppl 2):S190-204. https://doi.org/10.1086/652401.

8. Abel G, Brunton C. Young people's use of condoms and their perceived vulnerability to sexually transmitted infections. Aust N Z J Public Health. 2005;29(3):254-60. https://doi.org/10.1111/j.1467-842X.2005.tb00764.x.

9. den Daas C, Häfner M, de Wit J. The impact of long-term health goals on sexual risk decisions in impulsive and reflective cognitive states. Arch Sex Behav. 2014;43(4):659-67. https://doi.org/10.1007/s10508-013-0183-0.

10. Ten Hoor GA, Ruiter RAC, van Bergen JEAM, Hoebe CJPA, Dukers-Muijrers NHTM, Kok G. Predictors of chlamydia trachomatis testing: perceived norms, susceptibility, changes in partner status, and underestimation of own risk. BMC Public Health. 2016;16(1):55. https://doi.org/10.1186/s12889-016-2689-6.

11. Wolfers ME, Kok G, Mackenbach JP, de Zwart O. Correlates of STI testing among vocational school students in the Netherlands. BMC Public Health. 2010;10:725. https://doi.org/10.1186/1471-2458-10-725.

12. Harder E, Thomsen LT, Frederiksen K, Munk C, Iftner T, van den Brule A, et al. Risk factors for incident and redetected chlamydia trachomatis infection in women: results of a population-based cohort study. Sex Transm Dis. 2016;43(2):113-9. https://doi.org/10.1097/OLQ.0000000000000394.

13. Sonnenberg P, Clifton S, Beddows S, Field N, Soldan K, Tanton C, et al. Prevalence, risk factors, and uptake of interventions for sexually transmitted infections in Britain: findings from the National Surveys of sexual attitudes and lifestyles (Natsal). Lancet. 2013;382(9907):1795-806. https://doi.org/10.1016/S01406736(13)61947-9.

14. Velicko I, Ploner A, Sparen P, Marions L, Herrmann B, Kuhlmann-Berenzon S. Sexual and testing behaviour associated with chlamydia trachomatis infection: a cohort study in an STI clinic in Sweden. BMJ Open. 2016;6(8): e011312. https://doi.org/10.1136/bmjopen-2016-011312.

15. Walker J, Tabrizi SN, Fairley CK, Chen MY, Bradshaw CS, Twin J, et al. Chlamydia trachomatis incidence and re-infection among young women-behavioural and microbiological characteristics. PLoS One. 2012;7(5):e37778. https://doi.org/10.1371/journal.pone.0037778.

16. Samkange-Zeeb F, Pottgen S, Zeeb H. Higher risk perception of HIV than of chlamydia and HPV among secondary school students in two German cities. PLoS One. 2013;8(4):e61636. https://doi.org/10.1371/journal.pone.0061636.

17. Wolfers ME, de Zwart O, Kok G. Adolescents in the Netherlands underestimate risk for sexually transmitted infections and deny the need for sexually transmitted infection testing. AIDS Patient Care STDs. 2011;25(5): 311-9. https://doi.org/10.1089/apc.2010.0186.

18. Gotz HM, van den Broek IV, Hoebe CJ, Brouwers EE, Pars LL, Fennema JS, et al. High yield of reinfections by home-based automatic rescreening of chlamydia positives in a large-scale register-based screening programme and determinants of repeat infections. Sex Transm Infect. 2013;89(1):63-9. https://doi.org/10.1136/sextrans-2011-050455.

19. Heijne JC, Herzog SA, Althaus CL, Low N, Kretzschmar M. Case and partnership reproduction numbers for a curable sexually transmitted infection. J Theor Biol. 2013;331:38-47. https://doi.org/10.1016/j.jtbi.2013.04.010.

20. LaMontagne D, Baster K, Emmett L, Nichols T, Randall S, McLean L, et al. Incidence and reinfection rates of genital chlamydial infection among women aged 16-24 years attending general practice, family planning and genitourinary medicine clinics in England: a prospective cohort study by the chlamydia recall study advisory group. Sex Transm Infect. 2007;83(4):292-303. https:/doi.org/10. 1136/sti.2006.022053.

21. Fortenberry JD, Brizendine EJ, Katz BP, Orr DP. Post-treatment sexual and prevention behaviours of adolescents with sexually transmitted infections. Sex Transm Infect. 2002;78(5):365-8. https://doi.org/10.1136/ sti.78.5.365.

22. Ward DJ, Rowe B, Pattison H, Taylor RS, Radcliffe KW. Reducing the risk of sexually transmitted infections in genitourinary medicine clinic patients: a systematic review and meta-analysis of behavioural interventions. Sex Transm Infect. 2005;81(5):386-93. https://doi.org/10.1136/sti.2004.013714.

23. Crosby RA, DiClemente R, Wingood GM, Salazar LF, Rose E, Levine D, et al. Associations between sexually transmitted disease diagnosis and subsequent sexual risk and sexually transmitted disease incidence among adolescents. Sex Transm Dis. 2004;31(4):205-8. https://doi.org/10.1097/01.OLQ.0000114940.07793.20.

24. Nielsen A, Marrone G, De Costa A. Chlamydia trachomatis among youthtesting behaviour and incidence of repeat testing in Stockholm County, Sweden 2010-2012. PLoS One. 2016;11(9):e0163597. https://doi.org/10.1371/ journal.pone.0163597.

25. Reed JL, Simendinger L, Griffeth S, Kim HG, Huppert JS. Point-of-care testing for sexually transmitted infections increases awareness and short-term abstinence in adolescent women. J Adolesc Health. 2010;46(3):270-7. https://doi.org/10.1016/j.jadohealth.2009.08.003.

26. Soetens LC, van Benthem BHB, Op de Coul EL. Chlamydia test results were associated with sexual risk behavior change among participants of the chlamydia screening implementation in the Netherlands. Sex Transm Dis. 2015;42(3):109-14. https://doi.org/10.1097/OLQ.0000000000000234.

27. Sznitman SR, Carey MP, Vanable PA, DiClemente RJ, Brown LK, Valois RF, et al. The impact of community-based sexually transmitted infection screening results on sexual risk behaviors of African American adolescents. J Adolesc Health. 2010;47(1):12-9. https://doi.org/10.1016/j.jadohealth.2009.12.024.

28. Garnett GP, Cousens S, Hallett TB, Steketee R, Walker N. Mathematical models in the evaluation of health programmes. Lancet. 2011;378(9790): 515-25. https://doi.org/10.1016/S0140-6736(10)61505-X.

29. Kretzschmar MEE, Turner KM, Barton PM, Edmunds WJ, Low N. Predicting the population impact of chlamydia screening programmes: comparative mathematical modelling study. Sex Transm Infect. 2009;85(5):359-66. https://doi.org/10.1136/sti.2009.036251.

30. Schmid BV, Over EAB, van den Broek IVF, op de Coul ELM, JEAM v B, JSA F, et al. Effects of population based screening for Chlamydia infections in the Netherlands limited by declining participation rates. PloS One. 2013;8(3): e58674. https://doi.org/10.1371/journal.pone.0058674.

31. van den Broek IVF, Van Aar F, van Oeffelen AAM, Op de Coul ELM Woestenberg PJ, Heijne JCM, et al. Sexually Transmitted Infections in the Netherlands in 2015. Bilthoven: Centre for Infectious Disease Control, National Institute for Public Health and the Environment (RIVM); 2016. Available from: http://www.rivm.nl/Documenten_en_publicaties/Wetenschappelijk/Rapporten/ 2016/juni/Sexually_transmitted_infections_in_the_Netherlands_in_2015

32. Kuyper $L$, de Wit J, Heijman T, Fennema H, van Bergen JEAM, Vanwesenbeeck I. Influencing risk behavior of sexually transmitted infection clinic visitors: efficacy of a new methodology of motivational preventive counseling. AIDS Patient Care STDs. 2009;23(6):423-31. https:/doi.org/10.1089/apc.2008.0144.

33. Geisler WM, Lensing SY, Press CG, Hook EW 3rd. Spontaneous resolution of genital chlamydia trachomatis infection in women and protection from reinfection. J Infect Dis. 2013;207(12):1850-6. https://doi.org/10.1093/infdis/it094.

34. Kampman CIG, Koedijk FDH, Driessen-Hulshof HCM, Hautvast JLA, Van den Broek IVF. Retesting young STI clinic visitors with urogenital chlamydia trachomatis infection in the Netherlands; response to a text message reminder and reinfection rates: a prospective study with historical controls. Sex Transm Infect. 2015;92(2):124-9. https://doi.org/10.1136/sextrans-2015-052115.

35. Götz HM, Bom RJ, Wolfers ME, Fennema J, van den Broek IV, Speksnijder AG et al. Use of Chlamydia trachomatis high-resolution typing: an extended case study to distinguish recurrent or persistent infection from new infection. Sex Transm Infect. 2013;90(2):155-60. https://doi.org/10.1136/ sextrans-2013-051218.

36. Mollers M, Scherpenisse M, van der Klis FR, King AJ, van Rossum TG, van Logchem EM, et al. Prevalence of genital HPV infections and HPV serology in adolescent girls, prior to vaccination. Cancer Epidemiol. 2012;36(6):51924. https://doi.org/10.1016/j.canep.2012.07.006.

37. van Bergen JEAM, Fennema JSA, van den Broek IVF, Brouwers EEHG, de Feijter EM, Hoebe CJPA, et al. Rationale, design, and results of the first screening round of a comprehensive, register-based, chlamydia screening implementation programme in the Netherlands. BMC Infect Dis. 2010;10(1): 293. https://doi.org/10.1186/1471-2334-10-293.

38. van den Broek IVF, Sukel B, Bos H, and den Daas C. Evaluation of online providers of STI self-tests in the Netherlands [in Dutch]. Bilthoven, the 
Netherlands: RIVM 2016. Available from: http://www.rivm.nl/Documenten_ en_publicaties/Wetenschappelijk/Rapporten/2016/september/Evaluatie van_het_aanbod_van_online_aanbieders_van_soa_zelftesten_in_Nederland.

39. Vriend HJ, Boot HJ, van der Sande MA. Type-specific human papillomavirus infections among young heterosexual male and female STI clinic attendees. Sex Transm Dis. 2012;39(1):72-8. https://doi.org/10.1097/OLQ. 0b013e318235b3b0.

40. Formdesk. Formdesk Innovero Software Solutions B.V. Wassenaar, The Netherlands. 2017.

41. Blais AR, Weber EU. A domain-specific risk-taking (DOSPERT) scale for adult populations. Judgm Decis Mak. 2006;1 (1):33-47.

42. Carey MP, Carey KB, Weinhardt LS, Gordon CM. Behavioral risk for HIV infection among adults with a severe and persistent mental illness: patterns and psychological antecedents. Community Ment Health J. 1997;33(2):13342. https://doi.org/10.1023/A:1022423417304.

43. de Graaf H, Meijer S, Poelman J, Vanwesenbeeck I. Seks onder je 25e: Seksuele gezondheid van jongeren in Nederland anno 2005 [In Dutch]. Delft: Eburon Uitgeverij BV; 2005.

44. Dew AF, Henley TB. Reconsidering unique invulnerability in the context of sexual behavior. J Gend Cult Health. 1999;4(4):307-13.

45. van der Velde FW, Hooykaas C, van der Pligt J. Risk perception and behavior: pessimism, realism, and optimism about AIDS-related health behavior. Psychol Health. 1992;6(1-2):23-38. https://doi.org/10.1080/ 08870449208402018

46. Cyders MA, Littlefield AK, Coffey S, Karyadi KA. Examination of a short English version of the UPPS-P impulsive behavior scale. Addict Behav. 2014; 39(9):1372-6. https://doi.org/10.1016/j.addbeh.2014.02.013.

47. Cyders MA, Smith GT, Spillane NS, Fischer S, Annus AM, Peterson C. Integration of impulsivity and positive mood to predict risky behavior: development and validation of a measure of positive urgency. Psychol Assess. 2007;19(1):107-18. https://doi.org/10.1037/1040-3590.19.1.107.

48. Dewitte S, Schouwenburg HC. Procrastination, temptations, and incentives: the struggle between the present and the future in procrastinators and the punctual. Eur J Personal. 2002;16(6):469-89. https://doi.org/10.1002/per.461.

49. Lynam DR, Smith GT, Whiteside SP, Cyders MA. The UPPS-P: Assessing five personality pathways to impulsive behavior. West Lafayette: Purdue University; 2006

50. Whiteside SP, Lynam DR. The five factor model and impulsivity: using a structural model of personality to understand impulsivity. Personal Individ Differ. 2001;30(4):669-89. https://doi.org/10.1016/s0191-8869(00)00064-7.

51. Fishbein M, Ajzen I. Predicting and changing behavior: the reasoned action approach. New York: Taylor \& Francis; 2011.

52. Crandall CS, Moriarty D. Physical illness stigma and social rejection. Br J Soc Psychol. 1995;34(Pt 1):67. https://doi.org/10.1111/j.2044-8309.1995.tb01049.x.

53. Penke L. Revised sociosexual orientation inventory. Handbook of sexualityrelated measures. 3rd Ed. Edinburgh: Taylor \& Francis; 2011. p. 622-5.

54. Cunningham SD, Kerrigan D, Pillay KB, Ellen JM. Understanding the role of perceived severity in STD-related care-seeking delays. J Adolesc Health. 2005;37(1):69-74. https://doi.org/10.1016/j.jadohealth.2004.07.018.

55. Cunningham SD, Kerrigan DL, Jennings JM, Ellen JM. Relationships between perceived STD-related stigma, STD-related shame and STD screening among a household sample of adolescents. Perspect Sex Reprod Health. 2009:41(4):225-30.

56. Cunningham SD, Tschann J, Gurvey JE, Fortenberry JD, Ellen JM. Attitudes about sexual disclosure and perceptions of stigma and shame. Sex Transm Infect. 2002;78(5):334-8. https://doi.org/10.1136/sti.78.5.334.

57. Barkley TW, Burns JL. Factor analysis of the condom use self-efficacy scale among multicultural college students. Health Educ Res. 2000;15(4):485-9. https://doi.org/10.1093/her/15.4.485.

58. Robins RW, Hendin HM, Trzesniewski KH. Measuring global self-esteem: construct validation of a single-item measure and the Rosenberg selfesteem scale. Personal Soc Psychol Bull. 2001;27(2):151-61. https://doi.org/ $10.1177 / 0146167201272002$.

59. Mollema L, De Melker H, Hahné S, Van Weert J, Berbers G, and Van Der Klis F. PIENTER 2-project: second research project on the protection against infectious diseases offered by the national immunization programme in the Netherlands. 2010. Available from: http://www.rivm. nl/Documenten_en_publicaties/Wetenschappelijk/Rapporten/2010/maart/ PIENTER_2_project_second_research_project_on_the_protection_against_ infectious_diseases_offered_by_the_national_immunization_programme_ in_the_Netherlands.
60. van den Broek IVF. Chlamydia screening implementation Netherlands: impact evaluation and cost effectiveness. RIVM: Bilthoven; 2012. Available from: http://www.rivm.nl/en/Documents_and_publications/Scientific/ Reports/2012/juli/Chlamydia_Screening_Implementation_Netherlands_ impact_evaluation_and_cost_effectiveness

61. van den Broek IVF, van Bergen JE, Brouwers EE, Fennema JS, Gotz HM, Hoebe $\mathrm{CJ}$, et al. Effectiveness of yearly register-based screening for chlamydia in the Netherlands: controlled trial with randomised stepped wedge implementation. BMJ. 2012;345:e4316. https://doi.org/10.1136/bmj.e4316.

62. Estabrooks P, You W, Hedrick V, Reinholt M, Dohm E, Zoellner J. A pragmatic examination of active and passive recruitment methods to improve the reach of community lifestyle programs: the talking health trial. Int J Behav Nutr Phys Act. 2017;14(1):7. https://doi.org/10.1186/s12966-017-0462-6.

63. Sauermann H, Roach M. Increasing web survey response rates in innovation research: an experimental study of static and dynamic contact design features. Res Policy. 2013;42(1):273-86. https://doi.org/10.1016/j.respol.2012.05.003.

64. StataCorp. Stata Statistical Software: Release 13. College Station, Austin, Texas: StataCorp LP; 2013.

65. Mevissen FEF, Meertens RM, Ruiter RAC, Mares M. Chlamydia prevention by influencing risk perceptions. Edited by Mihai mares. Rijeka: InTech; 2012.

66. Ethier KA, Kershaw TS, Niccolai LM, Lewis JB, Ickovics JR. Adolescent women underestimate their susceptibility to sexually transmitted infections. Sex Transm Infect. 2003;79(5):408-11. https://doi.org/10.1136/sti.79.5.408.

67. Ford CA, Jaccard J, Millstein SG, Bardsley PE, Miller WC. Perceived risk of chlamydial and gonococcal infection among sexually experienced young adults in the United States. Perspect Sex Reprod Health. 2004;36(6):258-64. https://doi.org/10.1363/psrh.36.258.04.

68. Herzog SA, Heijne JC, Scott P, Althaus CL, Low N. Direct and indirect effects of screening for chlamydia trachomatis on the prevention of pelvic inflammatory disease: a mathematical modeling study. Epidemiology. 2013; 24(6):854-62. https://doi.org/10.1097/EDE.0b013e31829e110e.

69. Regan DG, Wilson DP, Hocking JS. Coverage is the key for effective screening of chlamydia trachomatis in Australia. J Infect Dis. 2008;198(3): 349-58. https://doi.org/10.1086/589883.

70. Datta SD, Torrone E, Kruszon-Moran D, Berman S, Johnson R, Satterwhite CL, et al. Chlamydia trachomatis trends in the United States among persons 14 to 39 years of age, 1999-2008. Sex Transm Dis. 2012;39(2):92-6. https://doi. org/10.1097/OLQ.0b013e31823e2ff7.

71. Rolstad S, Adler J, Rydén A. Response burden and questionnaire length: is shorter better? A review and meta-analysis. Value Health. 2011;14(8):1101-8. https://doi.org/10.1016/j.jval.2011.06.003.

72. Verelst F, Willem L, Beutels P. Behavioural change models for infectious disease transmission: a systematic review (2010-2015). J R Soc Interface. 2016;13(125):20160820. https://doi.org/10.1098/rsif.2016.0820.

73. Pines HA, Gorbach PM, Weiss RE, Shoptaw S, Landovitz RJ, Javanbakht M, et al. Sexual risk trajectories among MSM in the United States: implications for pre-exposure prophylaxis delivery. JAIDS. 2014;65(5):579-86. https://doi.org/ 10.1097/QAl.0000000000000101.

74. Heijne JCM, Herzog SA, Althaus CL, Tao G, Kent CK, Low N. Insights into the timing of repeated testing after treatment for chlamydia trachomatis: data and modelling study. Sex Transm Infect. 2013;89(1):57-62. https://doi.org/10. 1136/sextrans-2011-050468.

75. Hosenfeld CB, Workowski KA, Berman S, Zaidi A, Dyson J, Mosure D, et al. Repeat infection with chlamydia and gonorrhea among females: a systematic review of the literature. Sex Transm Dis. 2009;36(8):478-89. https://doi.org/10.1097/OLQ.0b013e3181a2a933.

\section{Ready to submit your research? Choose BMC and benefit from:}

- fast, convenient online submission

- thorough peer review by experienced researchers in your field

- rapid publication on acceptance

- support for research data, including large and complex data types

- gold Open Access which fosters wider collaboration and increased citations

- maximum visibility for your research: over $100 \mathrm{M}$ website views per year

At BMC, research is always in progress.

Learn more biomedcentral.com/submissions 